\title{
ChemComm
}

\section{Synthesis and ligand-based reduction chemistry of boron difluoride complexes with redox-active formazanate ligands $\uparrow$}

50, 7431

Received 30th April 2014

Accepted 19th May 2014

DOI: $10.1039 / c 4 c c 03244 f$

www.rsc.org/chemcomm

\author{
M.-C. Chang and E. Otten*
}

\begin{abstract}
Mono(formazanate) boron difluoride complexes $\left(\mathrm{LBF}_{2}\right)$, which show remarkably facile and reversible ligand-based redox-chemistry, were synthesized by transmetallation of bis(formazanate) zinc complexes with boron trifluoride. The one-electron reduction product $\left[\mathrm{LBF}_{2}\right]^{-}\left[\mathrm{Cp}_{2} \mathrm{Co}\right]^{+}$and a key intermediate for the transmetallation reaction, the six-coordinate zinc complex $\left(\mathrm{L}\left(\mathrm{BF}_{3}\right)\right)_{2} \mathrm{Zn}$ were isolated and fully characterized.
\end{abstract}

The chemistry of coordination complexes bearing redox-active (or non-innocent) ligands has recently received increasing attention due to its potential application in small molecule activation and catalysis, ${ }^{1}$ and its relevance to biological (enzymatic) transformations. ${ }^{2}$ The most studied ligands in this class are dithiolenes/ dioxolenes, ${ }^{3} \alpha$-diimines ${ }^{4}$ and bis(imino)pyridines. ${ }^{5}$ Formazanates (1,2,4,5-tetraazapentadienyls), which are nitrogen-rich analogues of the well-know $\beta$-diketiminates, ${ }^{6}$ have received comparatively little attention as ligands in coordination chemistry. ${ }^{7}$ Unlike $\beta$-diketiminates, which have a NCCCN backbone, formazanates feature a NNCNN backbone; the two additional nitrogen atoms provide formazanates with redox-active properties. Specifically, the reduced form of formazanates should be relatively accessible and stable due to delocalization of the SOMO over all $4 \mathrm{~N}$ atoms. This is in a way related to the stability of the analogous organic verdazyl radicals, which may be obtained from formazan precursors. ${ }^{8}$ In previous studies, we found that bis(formazanate) zinc complexes such as $[\mathrm{PhNNC}(p \text {-tol) }) \mathrm{NNPh}]_{2} \mathrm{Zn}$ (1a) are capable of storing one or two electrons in the ligand frameworks to form stable singly- and doubly-reduced zinc complexes. ${ }^{9}$ The crystal structures of the reduced complexes show (weak) interactions between the internal nitrogen atoms of formazanate ligands and sodium counter cations. Based on this observation we anticipated that the reduction potential of bis(formazanate) zinc compounds could be altered by coordination to neutral Lewis acids. In the course of testing

Stratingh Institute for Chemistry, University of Groningen Nijenborgh 4,

9747 AG Groningen, The Netherlands. E-mail: edwin.otten@rug.nl

$\dagger$ Electronic supplementary information (ESI) available: Synthesis and characterization data for compounds 2a, b, 3a and 4b. CCDC 995403-995405. For ESI and crystallographic data in CIF or other electronic format see DOI: 10.1039/ c4cc03244f a range of Lewis acids for binding to $1 \mathrm{a}$, we found that $\mathrm{BF}_{3}$ reacts cleanly via salt metathesis, opening a high-yield synthetic route to obtain mono(formazanate) boron difluoride $\left(\mathrm{LBF}_{2}\right)$ complexes which are difficult to access otherwise, either from the parent formazan or formazanate salts ( $\mathrm{LK}$ or $\mathrm{LNa}$ ). A related formazanate diacetate compound $\mathrm{LB}(\mathrm{OAc})_{2}$ was described by Hicks and co-workers, ${ }^{7 b}$ and although spectroscopic data suggested ligand-based 1-electron redoxchemistry to occur in these compounds, the 'borataverdazyl' radical anions obtained were too unstable to allow full characterization. Here we report the synthesis and X-ray crystallographic characterization of $\mathrm{LBF}_{2}$ and the radical anion $\mathrm{LBF}_{2}{ }^{--}$, with the formation of a relatively stable 2-electron reduction product $\mathrm{LBF}_{2}{ }^{2-}$ confirmed by cyclic voltammetry. In addition, we provide evidence for the transmetallation pathway by characterization of a likely intermediate.

Mono(formazanate) boron difluoride complexes are readily accessible by transmetallation of bis(formazanate) zinc complexes with $\mathrm{BF}_{3} \cdot \mathrm{Et}_{2} \mathrm{O}$ in hot toluene. In the case of $(\mathrm{PhNNC}(p \text {-tol }) \mathrm{NNPh})_{2} \mathrm{Zn}$ (1a), a stoichiometric reaction does not go to completion, but full conversion is achieved by performing the reaction with 3 equivalents of $\mathrm{BF}_{3} \cdot \mathrm{Et}_{2} \mathrm{O}$ at $70{ }^{\circ} \mathrm{C}$ twice. During the reaction, a colour change from deep blue to red and the precipitation of a white solid (presumably $\mathrm{ZnF}_{2}$ ) was observed to indicate formation of mono(formazanate) boron difluoride complex ( $\mathrm{PhNNC}\left(p\right.$-tol) $\mathrm{NNPh} \mathrm{BF}_{2}$ (2a, Scheme 1), which was isolated as an air-stable, crystalline material in $86 \%$ yield. A single crystal X-ray diffraction study (Fig. S1, ESI $\dagger$ ) revealed a distorted tetrahedral boron centre, which is displaced out of the (planar) formazanate NNCNN backbone by $0.5 \AA$ A A similar bonding mode was observed for $\beta$-diketiminate complexes of Sc and attributed to steric interactions. ${ }^{10}$ In the absence of significant steric pressure in 2a, we ascribe the out-of-plane displacement of the $\mathrm{B}$ atom to packing effects; the observation of only one ${ }^{19} \mathrm{~F}$ NMR resonance for 2a even at low temperature is consistent with a lowenergy $C_{2 \mathrm{v}}$ symmetric structure through which the two ${ }^{19} \mathrm{~F}$ environments exchange. As is the case in its parent zinc complex 1a and the related mono(formazanate) boron diacetate complexes reported by Hicks and co-workers, ${ }^{7 b}$ full delocalization within the formazanate framework in 2a is indicated by the similar $\mathrm{N}-\mathrm{N}$ and $\mathrm{C}-\mathrm{N}$ bond lengths in the NNCNN backbone. 

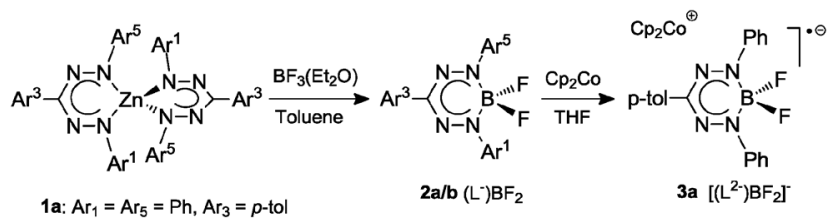
1a: $A r_{1}=A r_{5}=P h, A r_{3}=C_{6} F_{5}, A r_{5}=$ Mes
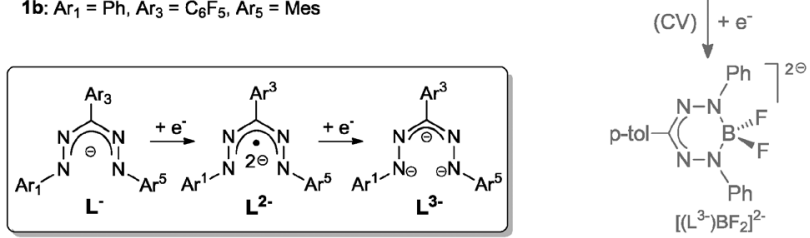

Scheme 1 Synthesis of mono(formazanate) boron difluoride complexes and their reduction products.

The redox-active nature of the formazanate ligand in $\mathbf{2 a}$ was established by cyclic voltammetry (CV) in THF solution with $\left[\mathrm{Bu}_{4} \mathrm{~N}\right]\left[\mathrm{PF}_{6}\right]$ electrolyte. Upon scanning to negative potentials, the $\mathrm{CV}$ shows two quasi-reversible one-electron redox processes (system I/I' and II/II' , Fig. 1) that can be assigned to formazanate-based reductions. The first redox-couple of $2 \mathbf{a}$ occurs at more positive potential $\left(E_{1 / 2}\left(\mathrm{I} / \mathrm{I}^{\prime}\right)=-0.98 \mathrm{~V} v s . \mathrm{Fc}^{0 /+}\right)$ than that in $1 \mathrm{a}\left(-1.31 \mathrm{~V} v s . \mathrm{Fc}^{0 /+}\right)^{9}$ and at similar potential as Hicks et al. reported for the analogous mono(formazanate) boron diacetate compound $\left(-0.86 \mathrm{~V} v s . \mathrm{Fc}^{\mathrm{0} /+}\right.$ in $\left.\mathrm{CH}_{3} \mathrm{CN}\right)^{7 b}$ A second redox-event is observed at more negative potential $\left(E_{1 / 2}\left(\mathrm{II} / \mathrm{II}^{\prime}\right)=-2.06 \mathrm{~V}\right.$ vs. $\left.\mathrm{Fc}^{0 /+}\right)$ but also this reduction is reversible. Based on these data, we infer that both one- and twoelectron reduction products of $2 \mathrm{a}$ are relatively stable and accessible. Importantly, the second reduction forms the dianion $\mathrm{LBF}_{2}{ }^{2-}$, in which two electrons have been added to a single formazanate ligand to result in a ' $\mathrm{L}^{3-}$, fragment coordinated to the boron centre (Scheme 1). Bard et al. recently explored the voltammetry of boron dipyrromethenes (BODIPY): in general these show oneelectron reductions at more negative potentials compared to $2 \mathrm{a}^{11}$ Related $\beta$-diketiminate compounds show irreversible reductions at much more negative potential $\left(E_{\mathrm{p}, \mathrm{red}} \sim-2.6 \mathrm{~V} v s . \mathrm{Fc}^{0 /+}\right){ }^{12}$

The first redox-couple of $2 \mathrm{a}$ occurs at $-0.98 \mathrm{~V} v s . \mathrm{Fc}^{0 /+}$, which suggests that cobaltocene is a suitable reducing agent to selectively synthesize a singly-reduced product. Upon reaction of $2 \mathbf{a}$ with one equivalent of $\mathrm{Cp}_{2} \mathrm{Co}$ in THF, an immediate colour change from red to green is observed to indicate formation of the radical species

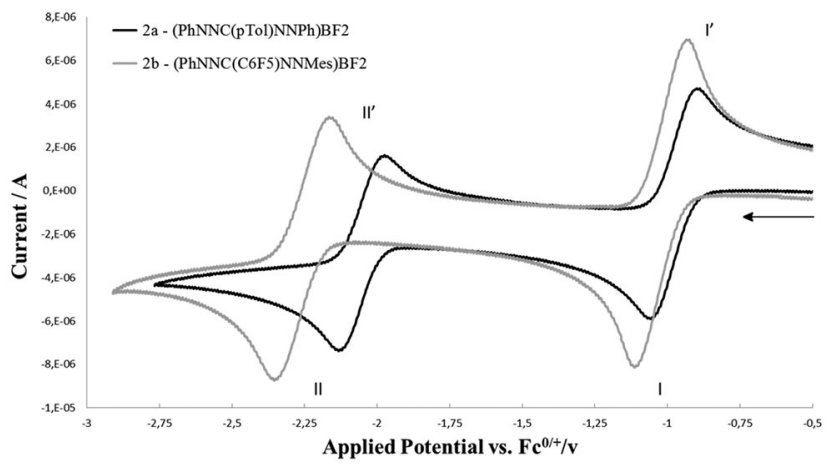

Fig. 1 Cyclic voltammetry of $\mathbf{2 a}$ and $\mathbf{2 b}(1.5 \mathrm{mM}$ solution in THF, $0.1 \mathrm{M}$ $\left.\left[\mathrm{Bu}_{4} \mathrm{~N}\right]\left[\mathrm{PF}_{6}\right]\right)$ recorded at $100 \mathrm{mV} \mathrm{s}^{-1}$.
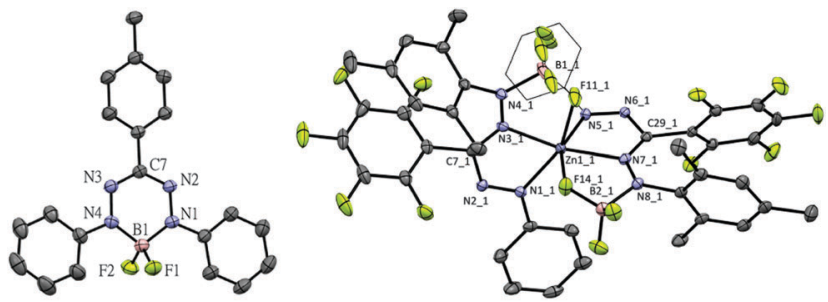

Fig. 2 Molecular structure of $3 a$ (left) and $4 \mathbf{b}$ (right) showing 50\% probability ellipsoids. For $3 \mathbf{a},\left[\mathrm{Cp}_{2} \mathrm{Co}\right]^{+}$cation and THF molecule are omitted; for $\mathbf{4 b}$, one of the two independent molecules is shown; for both, hydrogen atoms are omitted for clarity.

$\left[\mathrm{Cp}_{2} \mathrm{Co}\right]^{+}\left[\left(\mathrm{PhNNC}(p \text {-tol }) \mathrm{NNPh} \mathrm{BF}_{2}\right]^{-}\right.$(3a). In contrast to the reduction product of the diacetate analogue reported by Hicks, the difluoro complex 3a is stable in solution under an inert atmosphere for days and can even be boiled in THF-hexane without noticeable decomposition. The surprising stability of $\mathbf{3 a}$ is likely due to the strength of the B-F bonds in comparison to B-OAc. Crystals of 3a suitable for single-crystal X-ray diffraction analysis were obtained by diffusion of hexane into THF solution at room temperature in quantitative yield (Fig. 2, left). Compared with 2a, 3a has shortened B-N (av. $1.554 \AA$ for 2a vs. av. $1.535 \AA$ for 3a), elongated $\mathrm{N}-\mathrm{N}$ (av. $1.309 \AA$ for 2a vs. av. $1.362 \AA$ f for 3a) and elongated B-F (av. $1.376 \AA$ for $2 \mathrm{a} v s$. av. $1.410 \AA$ for 3a) bond lengths. The similar N-N bond lengths in $\mathbf{3 a}$ and the reduced $\mathrm{L}_{2} \mathrm{Zn}$ complexes ${ }^{9}$ suggest the ligand of $\mathbf{3 a}$ is a radical dianionic species $\left(\mathrm{L}^{2-}\right)$ in which the unpaired electron occupies a $\mathrm{N}-\mathrm{N}$ anti-bonding orbital.

UV-Vis absorption spectroscopy of neutral and anionic mono(formazanate) difluoride compounds provides additional evidence for ligand-based reduction and formation of the dianionic ligand radical $\left(\mathrm{L}^{2-}\right)$ (Fig. S3, ESI $\dagger$ ). The neutral compound 2a shows a single broad absorption in the visible at $521 \mathrm{~nm}$. In the case of 3a, absorption is at longer wavelength $(716 \mathrm{~nm})$ and at $454 \mathrm{~nm}$ with shoulders at 674 and $431 \mathrm{~nm}$, respectively. These absorption bands are in agreement with the presence of reduced formazanate ligands. ${ }^{9,13}$ The EPR spectrum of $\mathbf{3 a}$ shows a broad EPR signal in frozen THF with $g$-value of $\sim 2$ (Fig. S2, ESI $\dagger$ ). Attempts to synthesize and characterize the two-electron reduction product have so far been unsuccessful.

In order to expand the scope of transmetallation reactions from bis(formazanate) zinc complexes and boron trifluoride, the reaction of $\left(\mathrm{PhNNC}\left(\mathrm{C}_{6} \mathrm{~F}_{5}\right) \mathrm{NNMes}\right)_{2} \mathrm{Zn}$ (1) $)$ with $\mathrm{BF}_{3}$ was attempted. The colour of the reaction mixture fades from deep to light orange upon heating $\mathbf{1 b}$ in the presence of 3 eq. $\mathrm{BF}_{3} \mathrm{Et}_{2} \mathrm{O}$ at $70{ }^{\circ} \mathrm{C}$ overnight, but precipitation of $\mathrm{ZnF}_{2}$ was not observed. Orange crystals of the product $\mathbf{4} \mathbf{b}$ were obtained by slow diffusion of hexane into a toluene solution at $-30{ }^{\circ} \mathrm{C}$ in $85 \%$ yield (Fig. 2 , right). The crystal structure of 4b shows a distorted octahedral zinc centre. In the structure, there are two tridentate $\left(\mathrm{PhNNC}\left(\mathrm{C}_{6} \mathrm{~F}_{5}\right) \mathrm{NNMes}\left(\mathrm{BF}_{3}\right)\right)$ units coordinated to the $\mathrm{Zn}$ centre in a meridional fashion via two nitrogens and a fluorine atom to give a $[\mathrm{NNF}]_{2} \mathrm{Zn}$ compound. This unusual binding motif results from interaction of $\mathrm{BF}_{3}$ with the terminal nitrogen of the formazanate fragment (the NMes group), which gives rise to 2 five-membered chelate rings upon coordination to the $\mathrm{Zn}$ centre. To the best of our knowledge, the structural characterization of this $\mathrm{BF}_{3}$ 

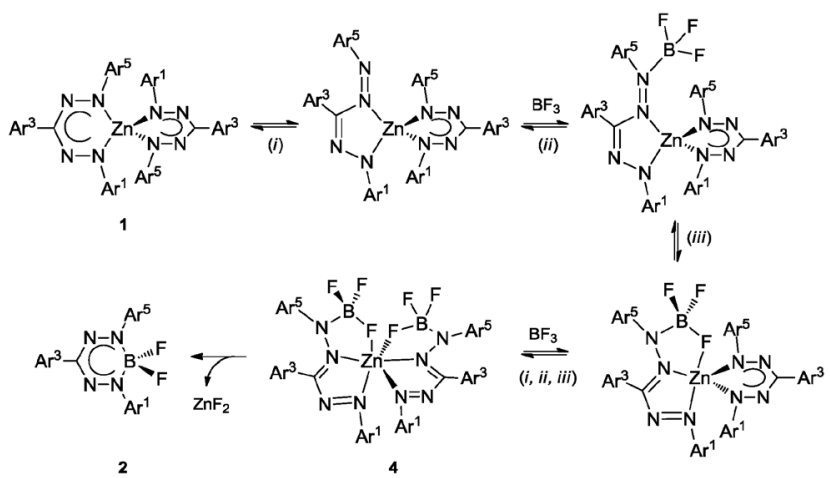

Scheme 2 Proposed mechanism of transmetallation from bis(formazanate) zinc complex to mono(formazanate) boron difluoride complex.

binding mode has no precedent in the literature, although the 'frustrated Lewis pair' (tmp) $\mathrm{MgCl} / \mathrm{BF}_{3}$ has been postulated to contain a B-F fragment appended to a $\mathrm{Mg}-\mathrm{N}(\mathrm{tmp})$ bond. ${ }^{14}$ The ${ }^{19} \mathrm{~F}-\mathrm{NMR}$ of $\mathbf{4 b}$ shows six distinct resonances with integration ratio of $1: 1: 3: 1: 1: 1$ (Fig. S6, ESI $\dagger$ ). Five resonances with the same integration $(1 \mathrm{~F})$ suggest that all $\mathrm{F}$ substituents of the $\mathrm{C}_{6} \mathrm{~F}_{5}$ ring are inequivalent due to hindered rotation around the $\mathrm{C}-\mathrm{C}_{6} \mathrm{~F}_{5}$ bond. The resonance integrating as $3 \mathrm{~F}$ shows ${ }^{11} \mathrm{~B}$ and ${ }^{10} \mathrm{~B}$ coupling features and can be assigned to the $\mathrm{BF}_{3}$ unit. The appearance of the $\mathrm{BF}_{3}$ group in the ${ }^{19} \mathrm{~F}$ NMR does not change upon cooling to $-55{ }^{\circ} \mathrm{C}$, which suggests that the barrier to rotation around the $\mathrm{N}-\mathrm{BF}_{3}$ bond is low. Conversely, heating an NMR sample of $\mathbf{4 b}$ to moderate temperature $\left(65^{\circ} \mathrm{C}\right.$ for $24 \mathrm{~h}$ ) does not result in changes in the spectroscopy, confirming that the octahedral $[\mathrm{NNF}]_{2} \mathrm{Zn}$ complex is quite stable. Upon heating the NMR tube to $130{ }^{\circ} \mathrm{C}$ overnight, full conversion to $\mathbf{2 b}$ is obtained. The ${ }^{19} \mathrm{~F}$ NMR spectrum of the new species shows signals characteristic for a freely rotating $\mathrm{C}_{6} \mathrm{~F}_{5}$ group and $\mathrm{BF}_{2}$ unit $\left({ }^{11} \mathrm{~B} \mathrm{NMR}:-1.34 \mathrm{ppm}\right.$, triplet with $\left.J_{\mathrm{B}-\mathrm{F}}=24 \mathrm{~Hz}\right)$. These data are consistent with formation of $\left[\mathrm{PhNNC}\left(\mathrm{C}_{6} \mathrm{~F}_{5}\right) \mathrm{NNMes}\right] \mathrm{BF}_{2}$ (2b). Cyclic voltammetry of $\mathbf{2 b}$ (Fig. 1) shows two quasi-reversible redox processes similar to $\mathbf{2 a}$ but shifted to more negative potential. This suggests that the electron-rich N-Mes group in $2 \mathbf{b}$ is more important than the electron-withdrawing $\mathrm{C}-\mathrm{C}_{6} \mathrm{~F}_{5}$ moiety in modulating the redox-potential of the formazanate fragment.

The sequential transformation $\mathbf{1 b} \rightarrow \mathbf{4 b} \rightarrow \mathbf{b} \mathbf{b}$ suggests that a six-coordinate species related to $\mathbf{4 b}$ is likely also involved in the formation of $\mathbf{2 a}$. Based on these observations, we propose the following mechanism for the transmetallation leading to compounds 4 (Scheme 2): (i) formazanate rearrangement from a 6- to a 5-membered chelate ring liberates the terminal $\mathrm{N}$-atom, (ii) $\mathrm{BF}_{3}$ binds to this terminal $\mathrm{N}$-atom and brings a B-F group in proximity of the $\mathrm{Zn}$ centre, and (iii) the $\mathrm{F}$ atom binds to the Lewis acidic $\mathrm{Zn}$ (II) centre to from a tridentate [NNF] ligand with two 5-membered chelate rings. Repeating this sequence for the second formazanate ligand results in formation of the $[\mathrm{NNF}]_{2} \mathrm{Zn}$ complex 4. Elimination of $\mathrm{ZnF}_{2}$ from this complex either occurs rapidly (in case of $1 \mathbf{a} \rightarrow$ ' $4 \mathbf{a}$ ' $\rightarrow \mathbf{2 a}$ ), or requires heating to proceed so that the intermediate can be isolated $(\mathbf{1 b} \rightarrow \mathbf{4 b} \rightarrow \mathbf{2 b})$. A reason for the increased stability of $\mathbf{4} \mathbf{b} v s$. that of putative intermediate $4 \mathbf{a}$ could be the favorable $\pi$-interactions between the electron-rich $\mathrm{N}$-Mes and the electron-poor $\mathrm{C}-\mathrm{C}_{6} \mathrm{~F}_{5}$ substituents, ${ }^{15}$ which are present only when the formazanate ligands adopt a 5-membered chelate ring.

In conclusion, transmetallation of bis(formazanate)zinc complexes with $\mathrm{BF}_{3} \cdot \mathrm{Et}_{2} \mathrm{O}$ provides a convenient entry into formazanate boron chemistry. The reaction likely occurs via initial binding of $\mathrm{BF}_{3}$ to the formazanate ligand. This pathway is possible through the flexibility of the NNCNN backbone to adopt 5-membered chelate ring isomers, which are inaccessible to their $\beta$-diketiminate congeners. One-electron reduction of $\mathrm{LBF}_{2}$ results in a fully characterized stable ligand-based radical, and cyclic voltammetry confirms a second reduction is possible, allowing access to three oxidation states $\left(\mathrm{LBF}_{2}{ }^{\mathrm{O}-1 /-2}\right)$ that are all based the redox-chemistry of a single formazanate ligand. The further development of this unique class of stable redox-active ligands towards applications in coordination chemistry and catalysis is the focus of ongoing work in our laboratory.

\section{Notes and references}

1 (a) P. J. Chirik and K. Wieghardt, Science, 2010, 327, 794; (b) V. Lyaskovskyy and B. de Bruin, ACS Catal., 2012, 2, 270; (c) V. K. K. Praneeth, M. R. Ringenberg and T. R. Ward, Angew. Chem., Int. Ed., 2012, 51, 10228.

2 (a) L. Que and W. B. Tolman, Nature, 2008, 455, 333; (b) J. B. Broderick, B. R. Duffus, K. S. Duschene and E. M. Shepard, Chem. Rev., 2014, 114, 4229.

3 (a) Prog. Inorg. Chem., ed. K. D. Karlin and E. I. Stiefel, John Wiley \& Sons, Inc., Hoboken, New Jersey, 2004, vol. 52; $(b)$ W. Kaim and B. Schwederski, Coord. Chem. Rev., 2010, 254, 1580; (c) R. Eisenberg and H. B. Gray, Inorg. Chem., 2011, 50, 9741.

4 (a) H. Tsurugi, T. Saito, H. Tanahashi, J. Arnold and K. Mashima, J. Am. Chem. Soc., 2011, 133, 18673; (b) S. J. Kraft, U. J. Williams, S. R. Daly, E. J. Schelter, S. A. Kozimor, K. S. Boland, J. M. Kikkawa, W. P. Forrest, C. N. Christensen, D. E. Schwarz, P. E. Fanwick, D. L. Clark, S. D. Conradson and S. C. Bart, Inorg. Chem., 2011, 50, 9838.

5 (a) M. W. Bouwkamp, A. C. Bowman, E. Lobkovsky and P. J. Chirik, J. Am. Chem. Soc., 2006, 128, 13340; (b) D. Zhu, I. Thapa, I. Korobkov, S. Gambarotta and P. H. M. Budzelaar, Inorg. Chem., 2011, 50, 9879; (c) A. M. Tondreau, S. C. E. Stieber, C. Milsmann, E. Lobkovsky, T. Weyhermüller, S. P. Semproni and P. J. Chirik, Inorg. Chem., 2013, 52, 635.

6 (a) L. Bourget-Merle, M. F. Lappert and J. R. Severn, Chem. Rev., 2002, 102, 3031; (b) Y.-C. Tsai, Coord. Chem. Rev., 2012, 256, 722.

7 (a) A. R. Siedle and L. H. Pignolet, Inorg. Chem., 1980, 19, 2052; (b) J. B. Gilroy, M. J. Ferguson, R. McDonald, B. O. Patrick and R. G. Hicks, Chem. Commun., 2007, 126; (c) J. B. Gilroy, P. O. Otieno, M. J. Ferguson, R. McDonald and R. G. Hicks, Inorg. Chem., 2008, 47, 1287; (d) J. B. Gilroy, M. J. Ferguson, R. McDonald and R. G. Hicks, Inorg. Chim. Acta, 2008, 361, 3388; (e) S. Hong, L. M. R. Hill, A. K. Gupta, B. D. Naab, J. B. Gilroy, R. G. Hicks, C. J. Cramer and W. B. Tolman, Inorg. Chem., 2009, 48, 4514.

8 (a) F. A. Neugebauer, Angew. Chem., Int. Ed. Engl., 1973, 12, 455; (b) R. G. Hicks, Verdazyls and Related Radicals Containing the Hydrazyl [R2N-NR] Group, in Stable Radicals, John Wiley \& Sons, Ltd, 2010, p. 245.

9 M.-C. Chang, T. Dann, D. P. Day, M. Lutz, G. G. Wildgoose and E. Otten, Angew. Chem., Int. Ed., 2014, 53, 4118.

10 P. G. Hayes, W. E. Piers, L. W. Lee, L. K. Knight, M. Parvez, M. R. Elsegood and W. Clegg, Organometallics, 2001, 20, 2533.

11 A. B. Nepomnyashchii and A. J. Bard, Acc. Chem. Res., 2012, 45, 1844.

12 S. M. Barbon, V. N. Staroverov, P. D. Boyle and J. B. Gilroy, Dalton Trans., 2014, 43, 240.

13 R. Kuhn and H. Trischmann, Monatsh. Chem., 1964, 95, 457.

14 M. Jaric, B. A. Haag, A. Unsinn, K. Karaghiosoff and P. Knochel, Angew. Chem., Int. Ed., 2010, 49, 5451.

15 (a) L. M. Salonen, M. Ellermann and F. Diederich, Angew. Chem., Int. $E d ., 2011,50,4808$; (b) C. R. Martinez and B. L. Iverson, Chem. Sci., 2012, 3, 2191. 